Review Article

\title{
A literature review of the current major intraoral digital impression systems and their accuracy
}

\author{
Maha Mezied*, Norah Alnasser, Reema Al Owaid, Rand Bakhsh, \\ Lama Alkhudhayr, Aseel Almazyad
}

Department of Dentistry, Riyadh Elm University, Riyadh, Saudi Arabia

Received: 26 May 2021

Accepted: 10 June 2021

\section{*Correspondence:}

Dr. Maha Mezied,

E-mail: Maha.s.s.mezied@hotmail.com

Copyright: (c) the author(s), publisher and licensee Medip Academy. This is an open-access article distributed under the terms of the Creative Commons Attribution Non-Commercial License, which permits unrestricted non-commercial use, distribution, and reproduction in any medium, provided the original work is properly cited.

\begin{abstract}
The accuracy of the intraoral digital impression systems has been previously reported to refer to the quality of the obtained data from the related scanning procedures, irrespective of the quality of the clinical outcomes and the estimated costs. Trueness and precision have been frequently found among studies in the literature as two terms describing the accuracy of the intraoral digital impression systems. Various digital impression modalities have been proposed among studies in the literature and were investigated for estimation of their accuracy. The paper aims to review and discuss the most common literature regarding the current common systems and their accuracy among the different studies in the literature. According to the results, Chairside Economical Restoration of Esthetic Ceramic (CEREC) systems appear to have the highest estimated rates of trueness and precision as compared to the other modalities while the iTero system appears to have the lowest estimated rates. However, some studies have reported contradicting results and the current evidence is mainly based on findings from in vitro investigations. Accordingly, further studies might be needed for further validation of the current evidence and strengthening the quality of the future potential implications for clinicians.
\end{abstract}

Keywords: Dentistry, Digital impression, Scanning, Accuracy, Validation

\section{INTRODUCTION}

Based on the recent advances in the field of digital dentistry, more effective and favorable outcomes can be obtained by using computer-aided design (CAD) and computer-aided manufacturing (CAM). Many technologies and modalities have been proposed based on the function and the type of the targeted tissue. Moreover, implications for efficacious intraoral digital impression procedures have aroused to innovate more efficacious modalities that can face the related difficulties. Approval on the application of intraoral digital impression systems was reported by both clinicians and patients due to the related favorable outcomes. ${ }^{1}$ Many advantages have been reported with using intraoral digital impression systems as easy repeatability, real-time visualization, cast pouring, being available and easy to conduct with no need to continue cleaning and time consumption, in addition to the selective capturing features of these modalities. ${ }^{2-5}$ Accuracy of the intraoral digital impression systems has been previously reported to refer to the quality of the obtained data from the related scanning procedures, irrespective of the quality of the clinical outcomes and the estimated costs. ${ }^{6}$ Trueness and precision have been frequently found among studies in the literature as two terms describing the accuracy of the intraoral digital impression systems. ${ }^{6}$

Various digital impression modalities have been proposed among studies in the literature and were investigated for estimation of their accuracy. ${ }^{7}$ The aim of the study was to review and discuss the most common literature regarding the current common systems and their accuracy among the different studies in the literature. 


\section{METHODS}

Evidence from the current literature shows that there are many current intraoral digital impression systems with their different accuracy. Among the reported intraoral digital impression systems. In the current review, it aims to focus on Lava C.O.S., CEREC, and iTero systems. Consequently, this literature review represents an extensive search that gathered data and information from medline, cochrane, and EMBASE databases on $10^{\text {th }}$ May 2021 using the medical subject headings (MeSH) and a combination of all possible related terms. This was followed by the manual search for studies in google scholar. Papers that discuss the major intraoral digital impression systems were screened for relevant information. The papers did not pose any limits on date, language, age of participants, or publication type.

\section{DISCUSSION}

\section{Lava C.O.S. system and the its accuracy}

According to the manufacturer of the modality, they reported that the modality is designed to be with a small scanner tip that is only $13.2 \mathrm{~mm}$ in diameter. Moreover, the system has a touch-screen to display and the images are processed by computer-based approaches while the light source can be observed as a blue light that is pulsating. ${ }^{8}$ Many in vitro investigations have previously estimated its accuracy of the modality. In the study by Ender and Mehl, the estimated precision and trueness for the modality were 60.1 and $40.3 \mu \mathrm{m}$ respectively. ${ }^{9}$ Another investigation by Patzelt et al also reported that the precision and trueness for the same modality were 37.9 and $38.0 \mu \mathrm{m}$, respectively. ${ }^{10}$ Another in vitro investigation by Patzelt et al investigated the accuracy of different digital impression modalities on edentulous jaw models reported that the estimated precision and trueness for the mandible and maxilla were 44.1 , and $24.6 \mu \mathrm{m}$ and 52.9 , and $30.8 \mu \mathrm{m}$ respectively. ${ }^{11}$ The accuracy of the Lava chairside oral scanner was also reported in a previous investigation by Patzelt et al which reported that the study was conducted on the full-arch polyurethane case, based on 14 priorly prepared abutments showed that precision and trueness for the modality were 13.77 and $67.50 \mu \mathrm{m}$ respectively. ${ }^{12}$

This system has been reported as a digital impression system first in 2006 and was found in the market two years later. A sampling of the active wavefront is the mechanism of action of the Lava C.O.S. (Lava Chairside Oral Scanner; 3M ESPE, Seefeld, Germany). ${ }^{13}$ This usually refers to the ability to use a single-lens digital impression system to obtain 3D data. Moreover, it has been reported that advanced algorithms for imaging processing are widely used within the techniques. The main functions of which are a generation of surface patches with favorable in- and out-of-focus prospectives. Based on the fact that the technique depends on a three-sensor modality to capture the clinical image from three different and adequate angles. ${ }^{13}$ A previous estimate showed that the system can capture 20 3D datasets/second, which has been reported to embody around 10,000 points of data for each captured scan. ${ }^{14}$ Accordingly, it has been estimated that the modality can result in the overall production of 2400 datasets of captured precise scans or what has also been previously estimated as 24 million points of captured precise data. The investigation which reported the modality for the first time reports that the modality has been designed to make sure that images and datasets of high quality are obtained due to the unique design of the modality that is mainly based on reducing the workforce that has been previously directed to prevent any potential overlapping of the captured pictures. ${ }^{14}$ It should be noted that a powder spray should be used to coat the targeted tooth before using the Lava C.O.S. system for digital impression. After forming a homogenous layer over the targeted tooth, scanning should be approached from posterior to anterior to cover the different aspects of the targeted tooth and obtain highquality images. ${ }^{15}$ Another advantage of the modality is that the obtained images can be timely observed during the operation over the displaying screen, which makes it easy for the performing dentists to decide whether the obtained images were adequate for processing and contain adequate information or not. ${ }^{15}$ The software can fix any pitfall of any potentially rescanned areas of the affected teeth to form a perfect image that can be used for adequate processing. Moreover, the system can effectively formulate a buccal image by combining the mandibular and maxillary aspects of the captured images. ${ }^{16}$

\section{CEREC system and the estimated accuracy}

Many investigations have also previously evaluated the accuracy of the CEREC system as a digital impression modality. A previous in vivo investigation by Ender et al recruited five individuals with observed complete dentition reported that the precision of the CEREC blue cam was $56.4 \mu \mathrm{m}$, while the estimated precision for the CEREC Omnicam was $48.6 \mu \mathrm{m} .{ }^{17}$ Another in vitro investigation by Hack and Patzelt also reported that the estimated precision and trueness for the CEREC AC OmniCam were found to be 16.2 and $45.2 \mu \mathrm{m}$ respectively. ${ }^{18}$ The previous investigation by Jeong et al also reported that the estimated precision and trueness for the used CEREC AC OmniCam that was used in their model of maxillary complete-arch of unprepared teeth were found to be 58.0 and $197.0 \mu \mathrm{m}$, respectively while the estimated same variables for the CEREC blue cam system were 116.0 and $378.0 \mu \mathrm{m}$ respectively. ${ }^{19}$ Another in vitro investigation by Renne et al used the custom maxillar- complete arch model that was used to scan complete and posterior sextant arches by CEREC Omnicom and CEREC Bluecam and other systems and found that the trueness and precision for both of these modalities were 101.5, and $133.4 \mu \mathrm{m}$ and 140.5, and $194.2 \mu \mathrm{m}$ respectively. ${ }^{20}$ In the same context, the accuracy of the same modalities was also investigated by a previous study by Lee et al using a single prepared molar tooth for a crown and reported that CEREC Bluecam and CEREC Omnicam had estimated trueness and precision of 17.5, and $12.7 \mu \mathrm{m}$ and 13.8 , and $12.5 \mu \mathrm{m}$ respectively. ${ }^{21}$ 
Recently, The accuracy of CEREC Omnicam was also reported in vitro investigation by Kim et al which reported that using markers, the trueness and precision were estimated to be 31.8 and $10.5 \mu \mathrm{m}$ respectively. ${ }^{22}$ In an in vivo investigation, Kuhr et al reported that the deviation was minimum and less severe as observed within the control group than other groups which included CEREC application; however, they also reported that the least deviation with CEREC Omnicam was observed within the intermolar distance as observed among their population. ${ }^{23}$

\section{iTero system and the reported accuracy}

This common digital impression modality was also reported among various studies in the literature; however, most of these studies are in vitro investigations, and validation in human populations is still needed. In an in vitro investigation, Anh et al estimated the accuracy of iTero digital impression systems in their study which included four models with different four arches including an ideal arch, one arch with mild crowding, another with moderate, and the fourth with severe crowding, all of which were maxillary of unprepared teeth. ${ }^{24}$ They reported that the accuracy for these four arches was 28.2, 29.6, 28.4, and 33.2 respectively. Another investigation was also conducted in the complete maxillary arch but with multiple cavities preparations to estimate the accuracy of different digital impression systems, including iTero. Kim and colleagues reported that the triangulation was $73.50 \mu \mathrm{m}$, wavefront sampling was $43.50 \mu \mathrm{m}$, the individual images were $70.55 \mu \mathrm{m}$, the video sequence was $56.45 \mu \mathrm{m}$, trueness according to confocal microscopy was $49.35 \mu \mathrm{m}$, optical coherence tomography was $137.0 \mu \mathrm{m}$. The authors also reported that trueness with and without powder coating was estimated to be 46.07 and $79.05 \mu \mathrm{m}$, respectively. The estimated accuracy for video sequences and individual images was also reported to be 56.45 and $70.55 \mu \mathrm{m}$ respectively. ${ }^{1}$ The accuracy of the modality was also reported in a previous in vivo investigation by Lee et al that reported that 32 study participants were recruited in the study and the iTero and TRIOS systems were used to scan the mandibular and maxillary arches. ${ }^{25}$ They reported that estimated average deviations of 0.057 and $0.069 \mathrm{~mm}$ were estimated between the two systems when scanning the maxilla and mandible, respectively. In an in vitro investigation that was conducted on a model of three prepared teeth with a laser-sintered cobalt-chromium master of the maxillary arches and scanning was done by different digital impression modalities including iTero scanner. The authors estimated the trueness for the iTero system to be $24.4 \mu \mathrm{m}$, which was higher than the calibrated CEREC Bluecam $(16.5 \mu \mathrm{m})$, but much less than the decalibrated CEREC Bluecam $(108.4 \mu \mathrm{m})$, the calibrated and decalibrated lave Chairside Oral Scanner systems (trueness $=34.9$ and $80.9 \mu \mathrm{m}$, respectively). ${ }^{26}$ The in vitro investigation by Patzelt et al also reported that the estimated trueness and precision for the iTero system were 49.6 and $40.5 \mu \mathrm{m}$ respectively, which were significantly lower than the estimated accuracy for the CEREC Bluecam and zfx intrascan but was comparable with lava C.O.S. digital impression systems. ${ }^{10}$ Although Patzelt et al estimated a higher accuracy for the modality in another in vitro investigation (Trueness= 144.2 for maxilla, and 191.5 $\mu \mathrm{m}$ for mandible; precision= 178.5 for maxilla, and 197.9 $\mu \mathrm{m}$ for mandible), it was still much lower than that estimated for the CEREC AC Bluecam and the $\mathrm{zfx}$ intraScan but was higher than the estimated accuracy for the lave Chairside Oral Scanner COS system. ${ }^{11}$ On the other hand, other in vitro investigations estimated that the reported accuracy for the iTero system in digital impression and scanning was comparable and even higher than other modalities within the same study, even including the CEREC Omnicam and CEREC Bluecam modalities. ${ }^{12,18,27}$ Therefore, it could be concluded that the modality has a middle-ground accuracy as a digital impression system as compared to other systems and modalities, and further investigations with populationbased designs are needed for further validation of the accuracy on humans.

\section{CONCLUSION}

The literature review discussion summarized the accuracy of the three most common digital impression systems that reported among studies. According to the results, CEREC systems appear to have the highest estimated rates of trueness and precision as compared to the other modalities, while the iTero system appears to have the lowest estimated rates. However, some studies have reported contradicting results that was evident from the findings of in vitro investigations. Accordingly, further studies might be needed for further validation of the current evidence which will strengthening the quality of the future potential implications for clinicians.

Funding: No funding sources

Conflict of interest: None declared

Ethical approval: Not required

\section{REFERENCES}

1. Kim RJ, Park JM, Shim JS. Accuracy of 9 intraoral scanners for complete-arch image acquisition: A qualitative and quantitative evaluation. J Prosthet Dent. 2018;120(6):895-903.

2. Zimmermann M, Mehl A, Mormann WH, Reich S. Intraoral scanning systems- a current overview. Int J Comput Dent. 2015;18(2):101-29.

3. Keul C, Stawarczyk B, Erdelt KJ, Beuer F, Edelhoff D, Guth JF. Fit of 4-unit FDPs made of zirconia and CoCr-alloy after chairside and labside digitalization-a laboratory study. Dent Mater. 2014;30(4):400-7.

4. Svanborg P, Skjerven H, Carlsson P, Eliasson A, Karlsson S, Ortorp A. Marginal and internal fit of cobalt-chromium fixed dental prostheses generated from digital and conventional impressions. Int J Dent. 2014;534382.

5. Ahrberg D, Lauer HC, Ahrberg M, Weigl P. Evaluation of fit and efficiency of CAD/CAM fabricated all-ceramic restorations based on direct 
and indirect digitalization: a double-blinded, randomized clinical trial. Clin Oral Investig. 2016;20(2):291-300.

6. Imburgia M, Logozzo S, Hauschild U, Veronesi G, Mangano C, Mangano FG. Accuracy of four intraoral scanners in oral implantology: a comparative in vitro study. BMC Oral Health. 2017;17(1):92.

7. Kravitz ND, Groth C, Jones PE, Graham JW, Redmond WR. Intraoral digital scanners. J Clin Orthod. 2014;48(6):337-47.

8. Galhano GA, Pellizzer EP, Mazaro JV. Optical impression systems for CAD-CAM restorations. J Craniofac Surg. 2012;23(6):575-9.

9. Ender A, Mehl A. Full arch scans: conventional versus digital impressions--an in-vitro study. Int $\mathbf{J}$ Comput Dent. 2011;14(1):11-21.

10. Patzelt SB, Emmanouilidi A, Stampf S, Strub JR, Att W. Accuracy of full-arch scans using intraoral scanners. Clin Oral Investig. 2014;18(6):1687-94.

11. Patzelt SB, Vonau S, Stampf S, Att W. Assessing the feasibility and accuracy of digitizing edentulous jaws. J Am Dent Assoc. 2013;144(8):914-20.

12. Patzelt SB, Bishti S, Stampf S, Att W. Accuracy of computer-aided design/computer-aided manufacturing-generated dental casts based on intraoral scanner data. J Am Dent Assoc. 2014;145(11):1133-40.

13. Shu S, Jian S. Intraoral Digital Impression Technique: A Review. J Prosthodont. 2015;24(4):313-21.

14. Syrek A, Reich G, Ranftl D, Klein C, Cerny B, Brodesser J. Clinical evaluation of all-ceramic crowns fabricated from intraoral digital impressions based on the principle of active wavefront sampling. J Dent. 2010;38(7):553-9.

15. Birnbaum N, Aaranson HA, Stephens C, Cohen B. 3D Digital Scanners: A High-Tech Approach to More Accurate Dental Impressions. Inside Dent. 2009;5.

16. Birnbaum NS, Aaronson HB. Dental impressions using 3D digital scanners: virtual becomes reality. Compend Contin Educ Dent. 2008;29(8):494.

17. Ender A, Attin T, Mehl A. In vivo precision of conventional and digital methods of obtaining complete-arch dental impressions. J Prosthet Dent. 2016;115(3):313-20.
18. Hack G, Sebastian BMP. Evaluation of the Accuracy of Six Intraoral Scanning Devices: An in-vitro Investigation. Sematic Scholar. 2015.

19. Jeong ID, Lee JJ, Jeon JH, Kim JH, Kim HY, Kim WC. Accuracy of complete-arch model using an intraoral video scanner: An in vitro study. J Prosthet Dent. 2016;115(6):755-9.

20. Renne W, Ludlow M, Fryml J, Schurch Z, Mennito A, Kessler R, et al. Evaluation of the accuracy of 7 digital scanners: An in vitro analysis based on 3dimensional comparisons. J Prosthet Dent. 2017;118(1):36-42.

21. Lee JJ, Jeong ID, Park JY, Jeon JH, Kim JH, Kim WC. Accuracy of single-abutment digital cast obtained using intraoral and cast scanners. J Prosthet Dent. 2017;117(2):253-9.

22. Kim JE, Amelya A, Shin Y, Shim JS. Accuracy of intraoral digital impressions using an artificial landmark. J Prosthet Dent. 2017;117(6):755-61.

23. Kuhr F, Schmidt A, Rehmann P, Wostmann B. A new method for assessing the accuracy of full arch impressions in patients. J Dent. 2016;55:68-74.

24. Anh JW, Park JM, Chun YS, Kim M, Kim M. A comparison of the precision of three-dimensional images acquired by 2 digital intraoral scanners: effects of tooth irregularity and scanning direction. Korean J Orthod. 2016;46(1):3-12.

25. Lee KM. Comparison of two intraoral scanners based on three-dimensional surface analysis. Prog Orthod. 2018;19(1):6.

26. Rehmann P, Sichwardt V, Wostmann B. Intraoral Scanning Systems: Need for Maintenance. Int J Prosthodont. 2017;30(1):27-9.

27. Ender A, Mehl A. In-vitro evaluation of the accuracy of conventional and digital methods of obtaining fullarch dental impressions. Quintessence Int. 2015;46(1):9-17.

Cite this article as: Mezied M, Alnasser N, Owaid RA, Bakhsh R, Alkhudhayr L, Almazyad A. A literature review of the current major intraoral digital impression systems and their accuracy. Int J Community Med Public Health 2021;8:3607-10. 